\title{
Studying the Linear and Nonlinear Optical Properties by Using Z-Scan Technique for CdS Thin Films Prepared by CBD Technique
}

\author{
Ahmed S. Jabbar ${ }^{1}$, Sabah I. Abbas ${ }^{2} \&$ Muneer H. Al-zubaidy ${ }^{1}$ \\ ${ }^{1}$ Department of Physics, College of science, Wasit University, al-kut, Iraq \\ ${ }^{2}$ Department of Medical physics, College of sciences, Al-Karkh University, Baghdad, Iraq \\ Correspondence: Ahmed S. Jabbar, Department of Physics, College of science, Wasit University, al-kut, Iraq. Tel: \\ 078-0852-6205,077-3537-3848. E-mail: ahmsa1988@gmail.com
}

Received: February 8, 2018

Accepted: March 14, 2018

Online Published: April 11, 2018

doi:10.5539/apr.v10n3p7

URL: https://doi.org/10.5539/apr.v10n3p7

\begin{abstract}
CdS films prepared by using CBD technique, linear optical properties tests measured by UV-3000 Nano from OPTIMA, nonlinear properties contained the nonlinear refractive index and nonlinear absorption coefficient by using single light beam source green semiconductor developed laser (SZ- 303 LASER) with material Nd:YVO4+KTP or Aluminum Alloy, and Wavelength Range is $(532 \mathrm{~nm})$, Beam Dimension 6 Meter distance Output Laser spot $18 \mathrm{~mm} \pm 2.0 \mathrm{~mm}$.
\end{abstract}

Keywords: nonlinear optical properties, SZ- 303 LASER, CdS, CBD

\section{Introduction}

CdS films prepared by using Chemical Bath Deposition as a preparation technique deposit at different durations started with (30 minutes) and ending in (120 minutes) by adding 30 minutes on every sample. CBD technique is the simplest method (Khallaf, 2009) and doesn't costs, also it gives a diversified thicknesses at every times that deposition time increased. Samples testes to calculate linear and nonlinear properties and that by using (UV-3000 Nano) to linear optical properties and (Z-scan method) for calculate the nonlinear optical properties. Z-scan technique is amongst the simplest and most sensitive of these techniques. The basic Z-scan technique has been described by Sheik-Bahae, Said, and Van Stryland (1989) and Sheik-Bahae et al. (1990), and a brief summary of the theory of the technique is presented here. The most important aspects to be considered for an experimental setup, along with some of the constraints that need to be placed on the design of the setup, will be highlighted (Sheik-Bahae \& Hasselbeck, 2000).

\section{Theory of Z-Scan Method}

The z-scan technique operates on the principle of moving the sample by focusing the Gaussian laser beam focused on it (Sheik-Bahae, Said, \& Van Stryland, 1989; Sheik-Bahae \& Hasselbeck, 2000). The intensity of the laser beam changes through the detector whenever the sample is moved and moved, due to the interaction between the medium and the laser light. A change in the mean means that the sample is experiencing a different laser beam intensity during the sample resulting from the interaction between the material and the intensity of the laser, dependent on the sample position $(\mathrm{z})$ relative to the focus $(\mathrm{z}=0)$. By measuring the transmitted power (the transmittance) through the sample as a function of z-position of the sample, information about the light-matter interaction can be extracted. The two nonlinear interactions that can be determined in this fashion are the sample's nonlinear index of refraction and nonlinear absorption coefficient (Sheik-Bahae \& Hasselbeck, 2000). To detect the nonlinear properties as the absorption coefficient and the nonlinear refractive index, there are two methods, each of which is calculated as one of them depending on the other : (i) The geometry in which a finite aperture is kept before the detector is known as a closed-aperture (CA) Z-scan; (ii) the geometry in which the aperture is removed to focus all the transmitted light into the detector is referred to as an open-aperture (OA) Z-scan (Costela et al., 1996; Hutchings, Sheik-Bahae, Hagan, \& Van Stryland, 1992; Chari et al., 1996). The main principle of zscan technique is based on transforming the phase distortion to amplitude distortions during beam propagation (Sheik-Bahae, Said, \& Van Stryland, 1989). 


\subsection{Closed-Aperture Z- Scan}

As shown in Figure (1), the sample is moved from the position $Z$ to $-Z$ and $+Z$, which is the propagation direction, with no open aperture before the detector where the energy is fixed to a certain extent while retaining the input energy pulse (Sheik-Bahae, Said, \& Van Stryland, 1989). The measured normalized transmittance of the sample is monitored through the aperture in the far field as a function of the position z. All this experimental process depend on the beam parameters and the samples thickness L. The size of the aperture is signified by its transmittance (S) is about $0.1<\mathrm{S}<0.5$ in all type of z-scan that done in all experimental for determining nonlinear refraction (Hutchings, Sheik-Bahae, Hagan, \& Van Stryland, 1992; Sheik-Bahae et al., 1990; Sheik-Bahae, Said, Wei, Hagan, \& Van Stryland, 1990). The change in permeability between the top and the bottom or the peak and the valley can be defined in this technique as :

$$
\Delta T_{p v}=T_{p}-T_{v}
$$

where $T_{p}$ and $T_{v}$ are the normalized peak and valley transmittances. The empirically determined relation between the induced on axis phase shift, $\Delta \Phi_{0}$, and $\Delta \mathrm{T}_{\mathrm{pv}}$ for a third-order nonlinear refractive process is,

$$
\Delta T_{p v}=0.406(1-s)^{0.27}\left|\Delta \emptyset_{0}\right|
$$

If the Z-scan aperture is closed to allow linear transmission of less than 10 percent or $0.1<S<0.5$, (Hutchings, Sheik-Bahae, Hagan, \& Van Stryland, 1992; Hutchings, Sheik-Bahae, Hagan, \& Van Stryland, 1992; Van Stryland $\&$ Sheik-Bahae, 1998) then equation (1) be:

$$
\Delta T_{p v}=0.406\left|\Delta \emptyset_{0}\right|
$$

As for the nonlinear refractive index, it is calculated by the difference between peak and valley in permeability measured by the following equation:

$$
n_{2}=\frac{\Delta \emptyset_{0}}{I_{0} L_{e f f}}
$$

where $\mathrm{k}$ is the wave vector the irradiance on axis $I_{0}$ is :

$$
I_{0}=\frac{2 P_{\text {peak }}}{\pi \omega_{0}^{2}}
$$

$P_{\text {peak }}$ : The peak power given by (Sheik-Bahae, Said, Wei, Hagan, \& Van Stryland, 1990):

$$
P_{\text {peak }}=\frac{E}{\Delta t}
$$

Where E: the energy of the pulsed laser, $\Delta t$ : the time duration, $\omega_{o}$ : the beam radius at the focal point.

$L_{e f f}$ : The effective length of the sample can be determined from the following formula (Hutchings, Sheik-Bahae, Hagan, \& Van Stryland, 1992; Chari et al., 1996; Van Stryland \& Sheik-Bahae, 1998):

$$
L_{e f f}=\frac{\left(1-e^{-\alpha_{\circ}} L\right)}{\alpha_{\circ}}
$$

where, $\mathrm{L}:$ the sample length, $\alpha_{\circ}:$ is the linear absorption coefficient given by :

$$
\alpha_{\circ}=\frac{1}{L \ln (1 / T)}
$$

where $\mathrm{T}$ is the linear transmittance.

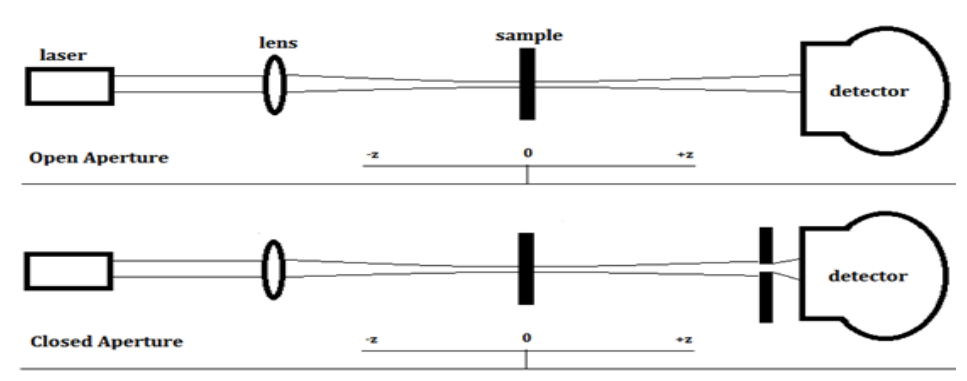

Figure 1. Open and closed Aperture of Z-Scan technique 


\subsection{Open Aperture Z-Scan}

Change in the intensity of the laser beam A concentration by the lens is measured in the second geometry of the z-scan system and as in Figure (1), where the closed aperture is raised and the beam is fully controlled on the detector which measures the change of laser beam intensity according to the sample movement on the propagation direction to calculate Nonlinear absorption. Each change in the intensity of the laser beam in the sample is only the result of the multi-photon absorption process during the process of moving the sample on the waist of the laser beam (Sheik-Bahae, Said, Wei, Hagan, \& Van Stryland, 1990). The intensity is greatest in the focal plane, the largest nonlinear absorption is observed. At the "tails" of the $Z$-scan signature, where $|Z|>>Z o$, the beam intensity is too weak to elicit nonlinear effects. The higher order of multi-photon absorption present in the measurement depends on the wavelength of light and the energy levels of the sample (Selvan et al., 2002). The normalized change in transmitted intensity can be approximated by the following equation (Hutchings, SheikBahae, Hagan, \& Van Stryland, 1992; Lu et al., 1997; Van Stryland \& Sheik-Bahae, 1998; Selvan et al., 2002):

$$
T(z)=\sum_{m=0}^{\infty} \frac{\left[\frac{\beta I_{0} L_{e f f}}{1+\left(Z / Z_{0}\right)^{2}}\right]^{m}}{(m+1)^{3 / 2}}
$$

where,

$Z:$ is the sample position at the minimum transmittance, $m$ : integer, $T(z):$ the minimum transmittance.

\section{Method}

CdS films prepared from thiourea $\left(\mathrm{CS}\left(\mathrm{NH}_{2}\right)_{2}\right)(0.2 \mathrm{M})$ as a source of sulfide ions, $(0.2 \mathrm{M})$ of cadmium chloride $\left(\mathrm{CdCl}_{2}\right)$ as a source of cadmium ions, $(0.5 \mathrm{M})$ of potassium hydroxide $(\mathrm{KOH})$, and using $(1.5 \mathrm{M})$ of ammonium nitrate $\left(\mathrm{NH}_{4} \mathrm{NO}_{3}\right)$ as a complex agents. Solution's Life time started when added thiourea. $\mathrm{pH}$ measured at 10.5, solution temperature was in $75^{\circ} \mathrm{C} \pm 5{ }^{\circ} \mathrm{C}$, deposition was done for four samples at ( $30 \mathrm{~min} ., 60 \mathrm{~min} ., 90 \mathrm{~min}$. and $120 \mathrm{~min}$.) all of them annealed at $500^{\circ} \mathrm{C}$. Figure (2) illustrate the increasing of thicknesses according to increasing in time deposition. Nonlinear systems tests setup with using single light beam source green semiconductor developed laser (SZ- 303 LASER) with material Nd:YVO4+KTP or Aluminum Alloy, wavelength $(532 \mathrm{~nm})$.

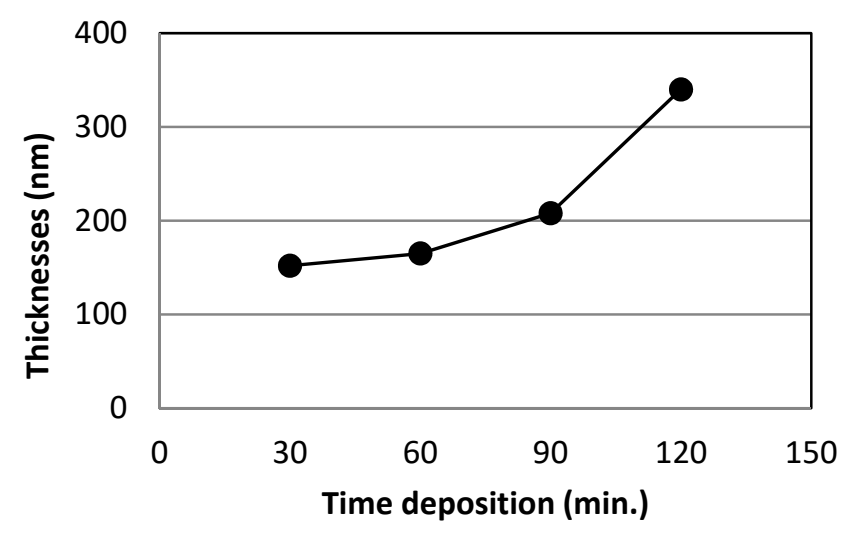

Figure 2. CdS films thicknesses (nm) as a function of time deposition (minutes)

\section{Results and Discussion}

\subsection{Linear Optical properties}

The visual properties involved were calculated the absorbance, transmittance, absorption coefficient $\alpha\left(\mathrm{cm}^{-1}\right)$, energy gap $\left(E_{\mathrm{g}}\right)$, refractive index $(\mathrm{n})$, and extinction coefficient $(\mathrm{k})$ by using UV-SP-3000 Nano. Transmittance Figure (3) shows gradually decreasing according to thicknesses increased that increasing because of increasing in time deposition, While absorbance Figure (4) shows increasing with increasing in time deposition. 


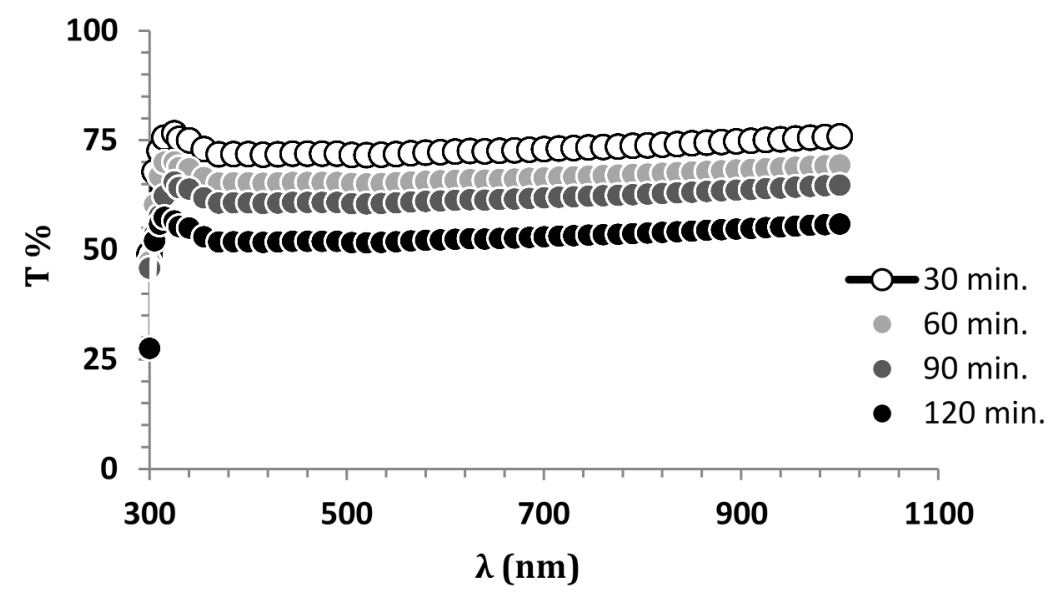

Figure 3. Optical Transmittance of the CdS thin films deposited at different time by CBD

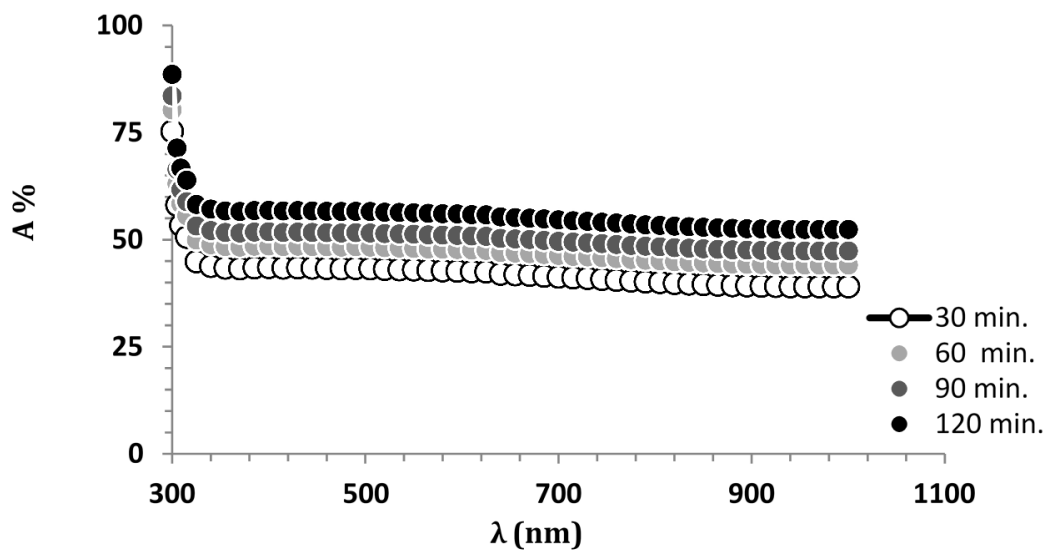

Figure 4. Absorbance spectrum of CdS films for different deposition time

Absorption coefficient calculated and plotted as a function to wavelength (nm), and shows variation values of $(\alpha)$ for four samples. The Figure (5) shows the absorption coefficient for CdS films. And it illustrated the Proportionality between thicknesses and absorption coefficient, where the increasing in thicknesses due to increasing in time deposition come upon that increasing in absorption coefficient.

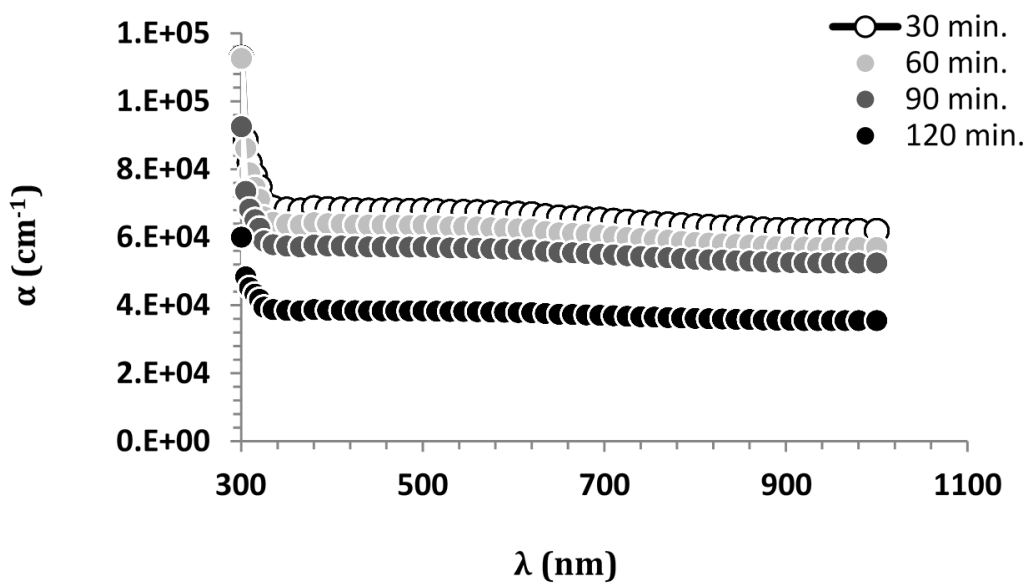

Figure 5. Absorption coefficient for CdS films 
Optical energy gap shows in Figure (6), it's clear that its decreasing with increasing of thicknesses. Generally band gap increasing or decreasing depending on grains size and thicknesses nothing else effected on energy gap.

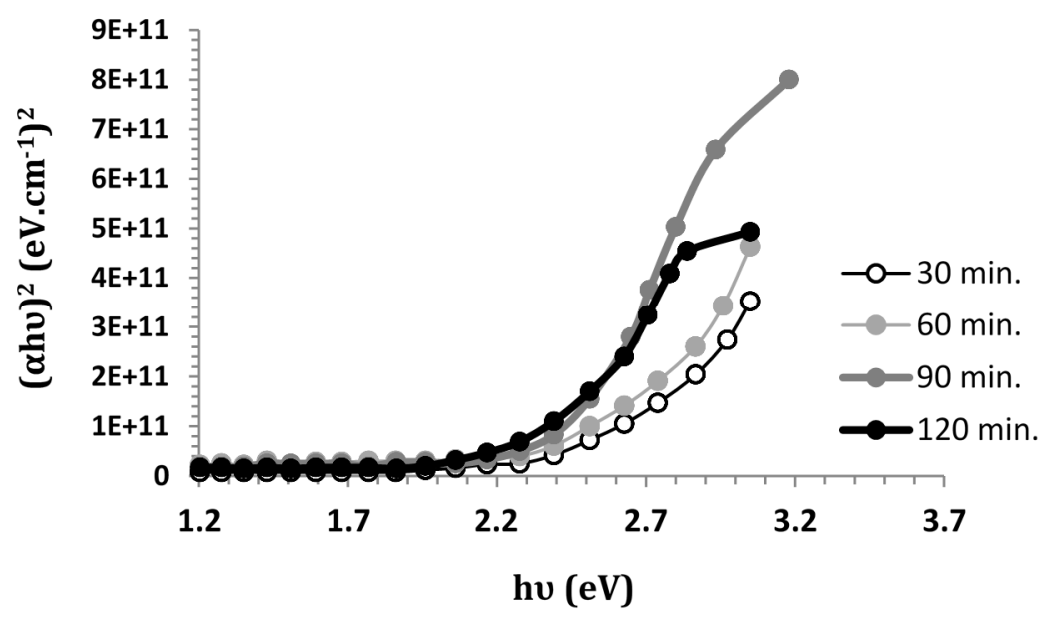

Figure 6. Energy gap; $(\alpha \mathrm{hv})^{2}$ as a function of photon energy of CdS films deposit at different durations

Refractive index (n), and extinction coefficient $(\mathrm{k})$ was calculated too for CdS films and shows the changing in the values. The Figure (7) \& Figure (8) illustrating the changing in both refractive index and extinction coefficient.

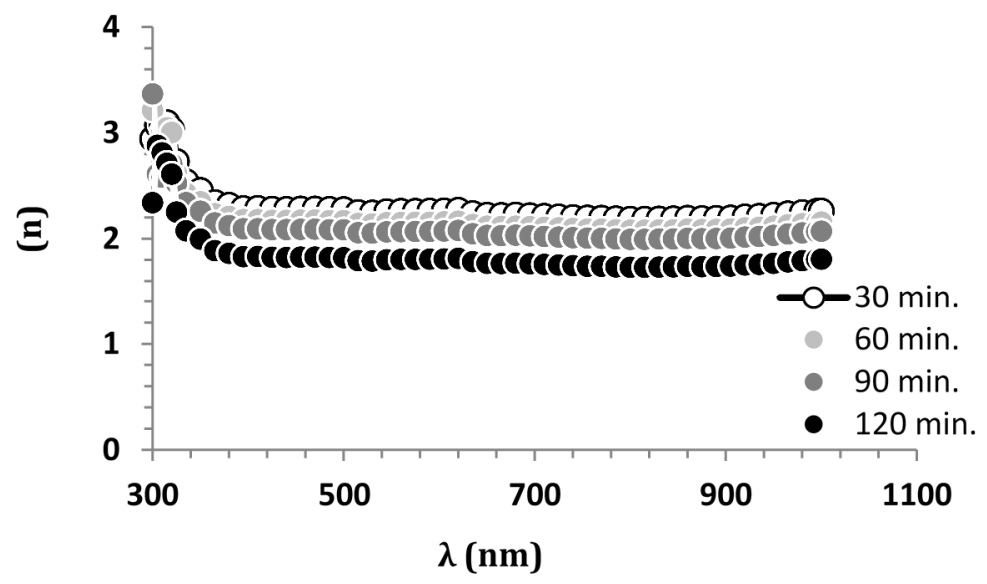

Figure 7. Refractive index (n) of CdS thin films

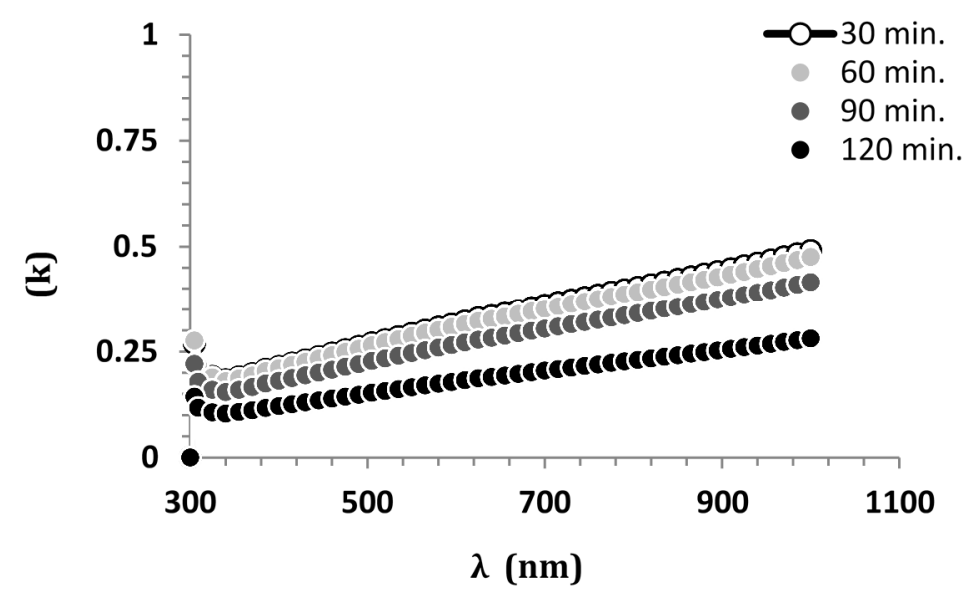

Figure 8. Extinction coefficient (k) for CdS thin films 


\section{Nonlinear Optical Properties}

Nonlinear optical properties contained nonlinear refractive index $\left(\mathrm{n}_{2}\right)$ in $\left(\mathrm{cm}^{2} / \mathrm{GW}\right)$ units, and nonlinear absorption coefficient $(\beta)$. Nonlinear refractive index measured through closed aperture $z$-scan and found that it is decreasing with increasing of thicknesses (time deposition increase). The nonlinear refractive index for 30 minute time deposit is more bigger $\left(8.83 \times 10^{-5} \mathrm{~cm}^{2} / \mathrm{GW}\right)$, for 60 minute $\left(7.68 \times 10^{-5} \mathrm{~cm}^{2} / \mathrm{GW}\right)$, for 90 minute $\left(5.45 \times 10^{-5}\right.$ $\left.\mathrm{cm}^{2} / \mathrm{GW}\right)$ and for last sample for 120 minute $\left(2.60 \times 10^{-5} \mathrm{~cm}^{2} / \mathrm{GW}\right)$, this results detects decreasing in nonlinear properties with increasing of thick films or thick media. The Figure (9) shows the normalized transmittance for CdS films.

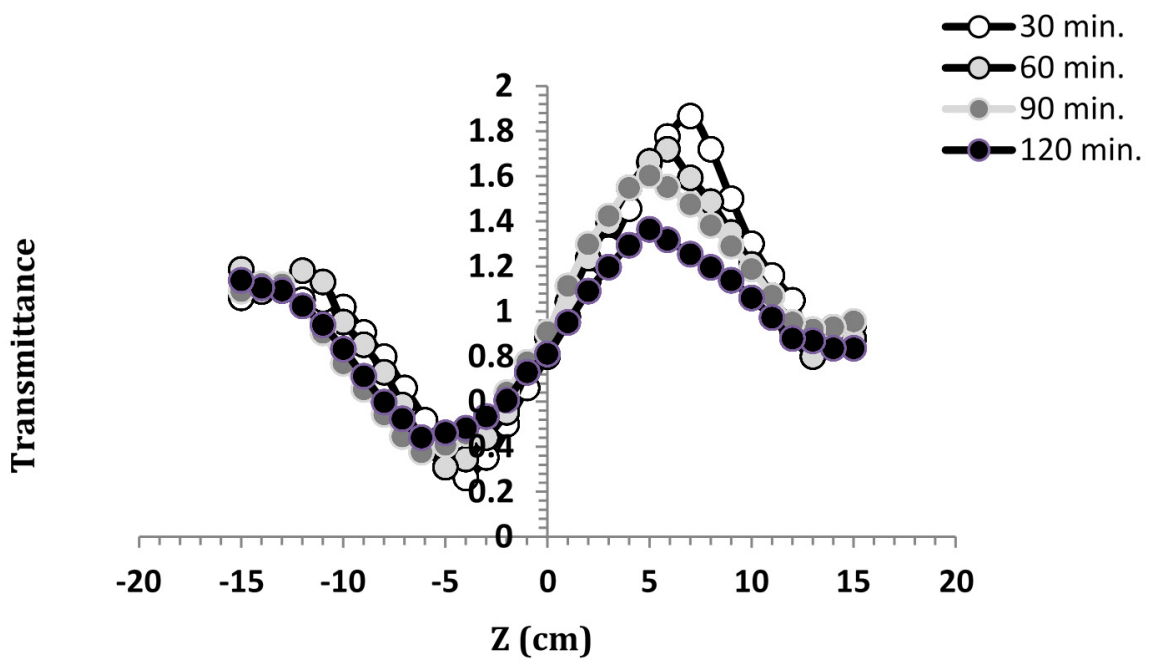

Figure 9. Closed Aperture Z-scan with SZ- 303 LASER for CdS thin films

The nonlinear refractive index $(\beta)$ measured by open aperture z-scan. This case corresponds to collecting all the transmitted light and therefore is insensitive to any nonlinear beam distortion due to nonlinear refraction. Figure (10) shows the normalized transmittance as a function of z-position $(\mathrm{cm})$ in case open aperture. The nonlinear absorption coefficient shows increasing with increasing in time deposit (thicknesses) of CdS thin films ant it was in values $(3.938,4.6964,5.2234$, and 5.2898).

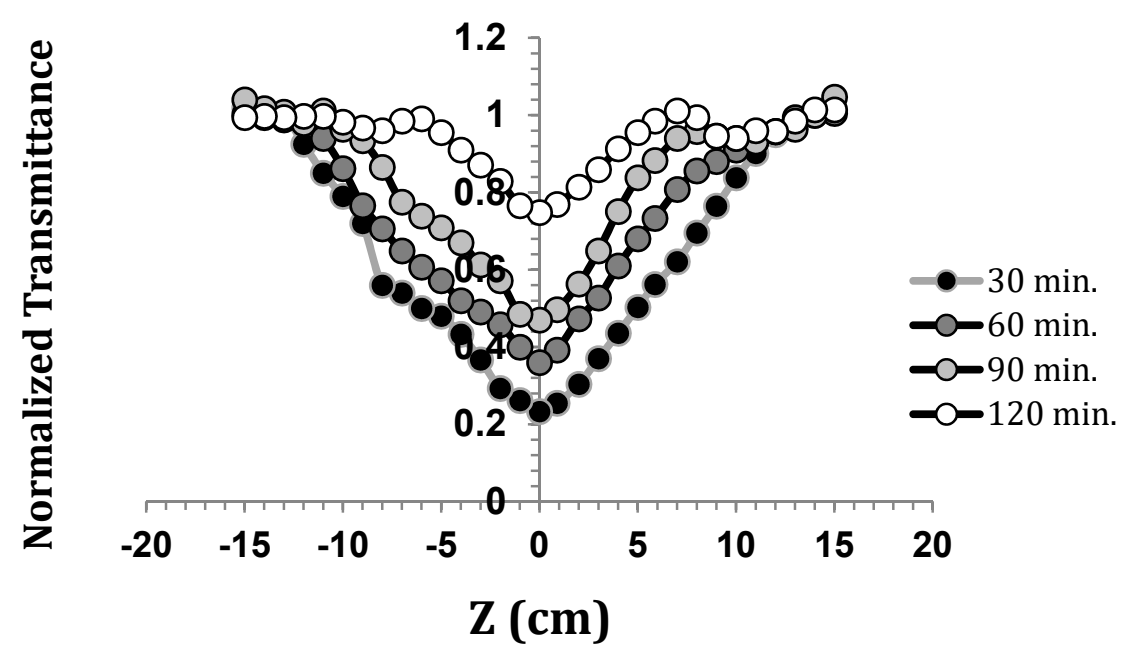

Figure 10. open Aperture Z-scan with SZ- 303 LASER for CdS thin films

The nonlinear absorption or nonlinear refractive index depending at laser wavelength but this dependence isn't strongly clear because there is much more affects at Nonlinear properties. 


\section{Conclusions}

The increasing in time deposition accompanied by increasing in thicknesses of films. And that lead to decreasing in absorbance and increasing in transmittance. The energy gap was in the general appropriate with grains size after reading the structural properties of CdS films. Nonlinear optical properties done by using (SZ- 303 LASER) with material Nd:YVO4+KTP or Aluminum Alloy and that usage considered the first using of this kind of lasers.

\section{References}

Chari, R., Mishra, S. R., Rawat, H. S., \& Oak, S. M. (1996). Reverse saturable absorption and optical limiting in indanthrone dyes. Applied Physics B, 62(3), 293-297. https://doi.org/10.1063/1.119464

Costela, A., Garcia-Moreno, I., Figuera, J. M., Amat-Guerri, F., Mallavia, R., Santa-Maria, M. D., \& Sastre, R. (1996). Solid-state dye lasers based on modified rhodamine 6G dyes copolymerized with methacrylic monomers. Journal of applied physics, 80(6), 3167-3173. https://doi.org/10.1063/1.363255

Gong, H. M., Wang, X. H., Du, Y. M., \& Wang, Q. Q. (2006). Optical nonlinear absorption and refraction of CdS and CdS-Ag core-shell quantum dots. The Journal of chemical physics, 125(2), 024707. https://doi.org/10.1063/1.2212400.

Hutchings, D. C., Sheik-Bahae, M., Hagan, D. J., \& Van Stryland, E. W. (1992). Kramers-Krönig relations in nonlinear optics. Optical and Quantum Electronics, 24(1), 1-30. https://doi.org/10.1007/BF01234275

Khallaf, H. M. (2009). Chemical Bath Deposition of Group Ii-vi Semiconductor Thin Films For Solar Cells Applications (Doctoral dissertation). University of Florida.

Lu, H. S., Volk, M., Kholodenko, Y., Gooding, E., Hochstrasser, R. M., \& DeGrado, W. F. (1997). Aminothiotyrosine disulfide, an optical trigger for initiation of protein folding. Journal of the American Chemical Society, 119(31), 7173-7180. https://doi.org/10.1021/ja970567o.

Selvan, S. T., Hayakawa, T., Nogami, M., Kobayashi, Y., Liz-Marzan, L. M., Hamanaka, Y., \& Nakamura, A. (2002). Dispersion of bound electronic nonlinear refraction in solids. J. Phys. Chem. B, 106(39), 10157-10162. https://doi.org/10.1109/3.89946

Sendhil, K., Vijayan, C., \& Kothiyal, M. P. (2006). Low-threshold optical power limiting of cw laser illumination based on nonlinear refraction in zinc tetraphenyl porphyrin. Optics \& Laser Technology, 38(7), 512-515. https://doi.org/10.1016/j.optlastec.2004.12.005

Sheik-Bahae, M., \& Hasselbeck, M. P. (2000). Third-order optical nonlinearities. Handbook of Optics, 4, 16-1.

Sheik-Bahae, M., Said, A. A., \& Van Stryland, E. W. (1989). High-sensitivity, single-beam n 2 measurements. Optics letters, 14(17), 955-957. https://doi.org/10.1364/OL.14.000955

Sheik-Bahae, M., Said, A. A., Wei, T. H., Hagan, D. J., \& Van Stryland, E. W. (1990). Sensitive measurement of optical nonlinearities using a single beam. IEEE journal of quantum electronics, 26(4), 760-769. https://doi.org/10.1109/3.53394

Sheik-Bahae, M., Said, A. A., Wei, T. H., Hagan, D. J., \& Van Stryland, E. W. (1990). Sensitive measurement of optical nonlinearities using a single beam. IEEE journal of quantum electronics, 26(4), 760-769. Retrieved from https://www.photonicssociety.org/images/files/publications/Newsletter/Feb2007

Van Stryland, E. W., \& Sheik-Bahae, M. (1998). Z-scan measurements of optical nonlinearities. Characterization techniques and tabulations for organic nonlinear materials, 18(3), 655-692.

\section{Copyrights}

Copyright for this article is retained by the author(s), with first publication rights granted to the journal.

This is an open-access article distributed under the terms and conditions of the Creative Commons Attribution license (http://creativecommons.org/licenses/by/4.0/). 